Research Journal of Applied Sciences 6 (1): 66-69, 2011

ISSN: $1815-932 \mathrm{X}$

(C) Medwell Journals, 2011

\title{
The Effect of Magnetic Water on Strength Parameters of Concrete
}

\author{
${ }^{1} \mathrm{M}$. Gholizadeh and ${ }^{2} \mathrm{H}$. Arabshahi \\ ${ }^{1}$ Department of Chemistry, ${ }^{2}$ Department of Physics, \\ Ferdowsi University of Mashhad, Mashhad, Iran
}

\begin{abstract}
A machine for magnetic water treatment is designed and its application on the ions contained in water has been investigated to examine the effect of magnetic water on concrete parameters. Strength parameters of concrete have been studied for $>104$ concrete samples including the nonmagnetic samples (made by ordinary water) and magnetic samples (made by magnetic water) with slump and compressive strength experiments. Based on slump experiments, magnetic samples were $7 \mathrm{~cm}$ more than nonmagnetic group and the average compressive strength of samples made by magnetic water was $23 \%$ more than that of samples made by ordinary water. The experimental results show the advantages of magnetic samples in concrete industry because of increase in plasticity, the efficiency and quality of concrete boosts in comparison with nonmagnetic samples.
\end{abstract}

$\underline{\text { Key words: Magnetic water, compressive strength, slump, plasticity, surface tension decrease, concrete, Iran }}$

\section{INTRODUCTION}

Magnetic water treatment machine was first invented in 1945 by a distinguished Belgian engineer. This machine which is currently utilized in $>50$ countries around the world such as America and Russia was practically introduced to the market since 1950 and as a result of a series of persistent and continuous studies it was developed into its present improved and perfect form AQUA CORRECT (Strum and Morgan, 1940; Munger et al., 1986; Kristina, 2001; Russell et al., 1997).

This machine contains a powerful magnet which is the source of production of magnetic energy. This powerful magnet is fixed in a small tube with such high technology that can create a magnetic field reaching a high rate of about 6500 Gauss. This machine simply works based on the electromagnetic induction principle which was introduced by Mickeal Faraday in 1832 .

Water passing through this machine undergoes the magnetic energy present there which influences the colliding particles, calcium carbonate molecules $\left(\mathrm{CaCO}_{3}\right)$, salts and other saline in water and changes their physical and electrical properties and creates a particular pattern.

This change in the electron pattern in ions leads to a lack of activity in forming compositions and no precipitation occurs. Also, magnetic energy reduces the surface tension of water by $10 \%$. However because of such changes, no suitable environment is provided for the formation of viscous deposits (adherence of calcium crystals and other substances) and in this way magnetic water with its unique and special properties is produced (Fig. 1). (a)

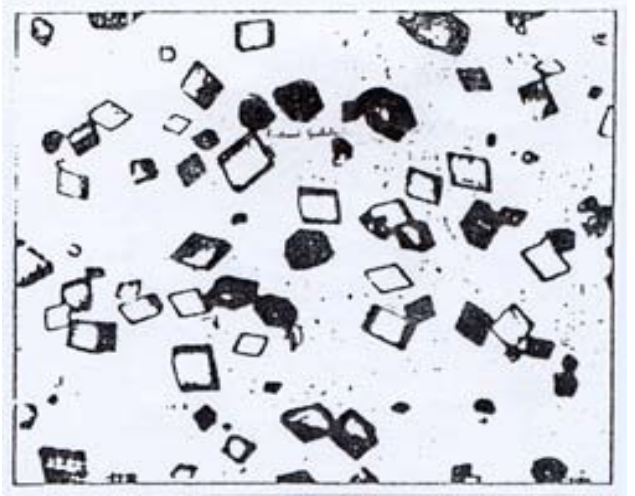

(b)

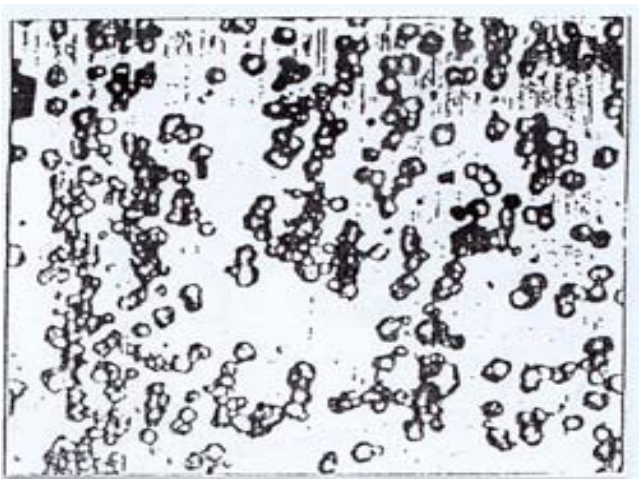

Fig. 1: (a) Microscopic representation of calcium carbonate crystals in water which is not filtered (magnified 600 times); (b) microscopic representation of calcium carbonate crystals in electromagnetic water (magnified 600 time)

Corresponding Author: M. Gholizadeh, Department of Chemistry, Ferdowsi University of Mashhad, Mashhad, Iran 
According to the Lorentz force $\mathrm{QV} \times \mathrm{B}$ in this machine, the output of magnetic anti-precipitation depends on the power of magnetic field imposed, velocity of water flow, magnetic force, number of particles with positive or negative charge in water and angle between particle velocity and applied magnetic field which is always upright and hence maximum effect of magnetic field is applied.

Water temperature has no significant effect on the magnetic anti-precipitation process and the machine itself is quite resistant toward high temperatures (Gholizadeh et al., 2008; Al-Qahtani, 1996; Coey and Cass, 2000).

\section{MATERIALS AND METHODS}

Concrete structure: Concrete is a proportionate mixture of four basic ingredients, sand, gravel, cement and water (under some conditions, other ingredients are added to achieve a certain objective but these are not among the basic ones).

In fact the main bulk of concrete is made of small and large pebbles (sand and grit) which are the stone construction materials and the chemical interactions between cement and water form a mixture which surrounds stone construction materials and adheres and consolidates them together.

To initiate chemical reactions in cement a limited amount of water is needed where as the water used in concrete composition is always much more than that. The water added is to increase the necessary utility and flexibility of concrete for filling all the angles of the mould and surrounding all the reinforcing bars.

By choosing different proportions of the ingredients of concrete, a wide variety of concrete with different resistance is gained. Indeed, the impact of water is very remarkable. That is why most recommended methods for mixture design of concrete have regarded water with importance and great sensitivity for its hydration nature. In order to make concrete, the usual natural water is suitable such as rainwater, stream water, etc.

River water can also be used if the chemical wastes of factories have not polluted it. Water with extra chlorine is harmful to reinforced concrete as it corrodes the armature framework.

Other kinds of water which are heavily polluted by oil, fat or other pollutants which negatively affect on the solidification or other properties of concrete must not be applied. The residue of plants, even a small amount is harmful to concrete and muddy water lessens the compressive strength of concrete. Water of swamps which are dark, stale and stinking and fizzy water such as $\mathrm{CO}_{2}$ and water containing gypsum, sulfate or chloride have all negative effects on concrete and must not be used. In dubious cases the water sample must be sent to laboratory for chemical analysis of water to determine its suitability for the construction of concrete.

Generally, water suitable for drinking is suitable enough for concrete construction (this is not always true such as water containing sugar which is drinkable but may not be suitable for concrete construction). However, taste, smell or source of water may not reject a kind of water by themselves.

If the impurities in water go beyond a certain level, this may greatly affect the time span of consolidation resistance and volume stability of concrete or may also corrode the steel.

Water used for concrete construction must be pure of any oil, acids bases, salts, organic or any other materials harmful to concrete. Using the standard water the machine for magnetic water treatment has been applied in many countries to make high quality concrete. Figure 2 and 3 show two example of magnetic concrete application.

(b)

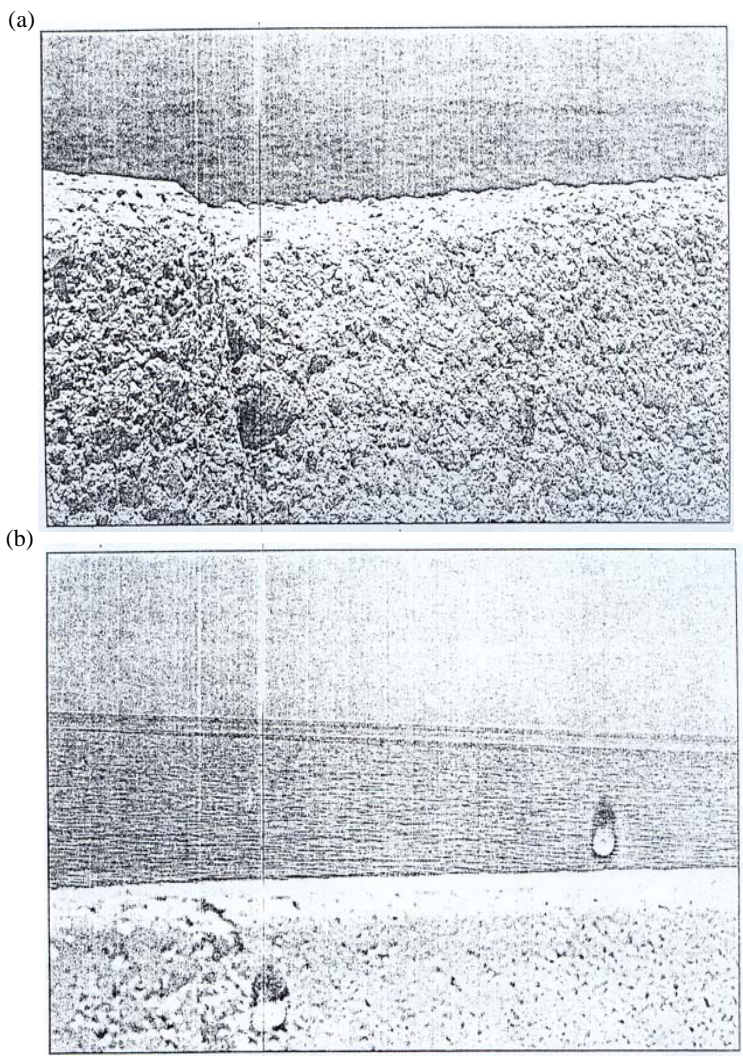

Fig. 2: Black sea coasts, (a) before repair (ordinary water); (b) after repair (magnetic water) 

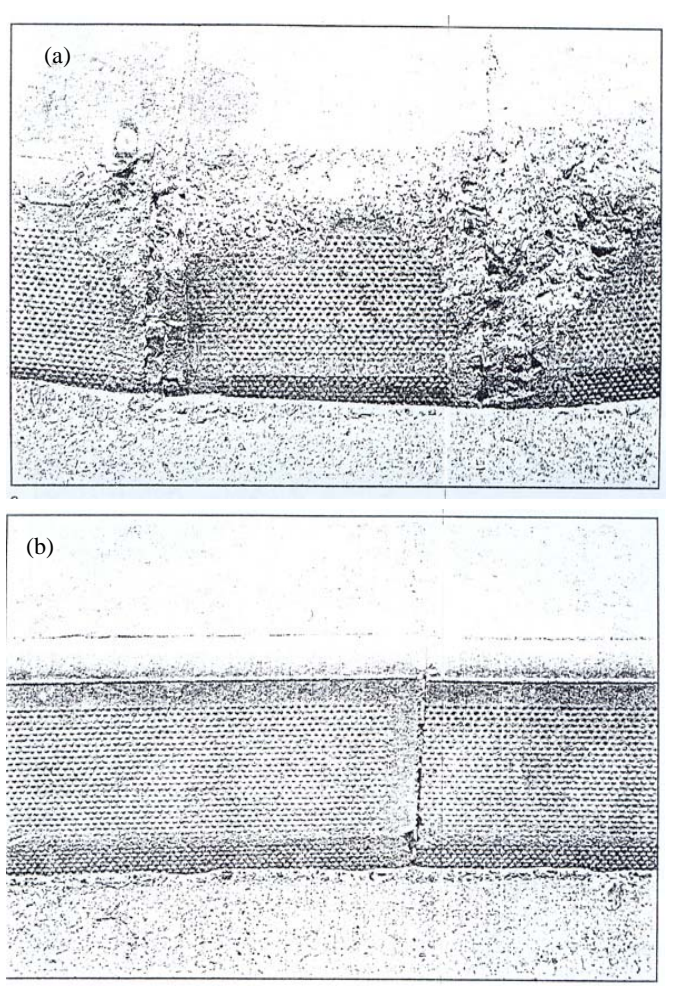

Fig. 3: Superstructure of Rostove Nodonove way; (a) before renovation (ordinary water); (b) after renovation (magnetic water)

\section{RESULTS AND DISCUSSION}

Generally the essential condition for a good concrete is a satisfactory compressive strength. A satisfactory compressive strength does not signify a certain degree of tolerance against compressive tensions but this condition is because of the fact that other properties of concrete are relevant to compressive strength.

Regarding this fact slump experiments were applied to examine concrete efficiency and compressive strength experiment to determine maximum strength of the samples against pressure. Therefore, 104 concrete samples were categorized within two groups, group (A), nonmagnetic samples which are made by ordinary water and group (B) magnetic samples which are made by magnetic water. Each group contained 52 samples both in cube and cylinder form to measure and analyze their strength separately. Based on the mixture design of concrete, some concrete samples with $35 \mathrm{~kg} \mathrm{~m}^{-3}$ standard were provided for both groups. These samples had the same condition in construction materials, grading and kind of cement. The only difference was the water applied which was drinkable water with two different states, ordinary and magnetic. As soon as concrete was prepared, slump experiment was
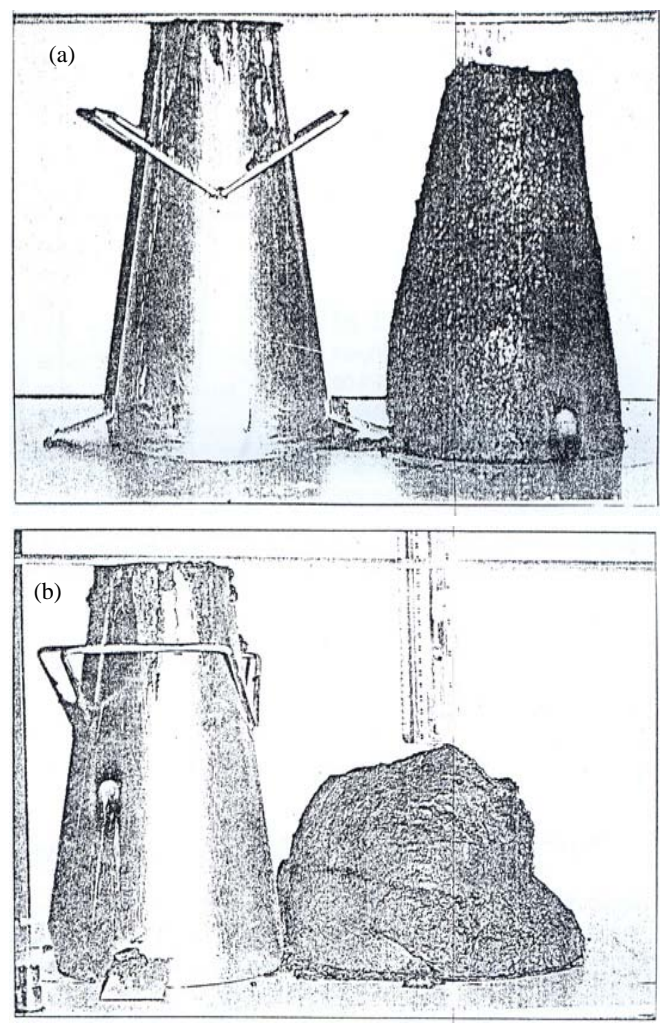

Fig. 4: Subsidence rate of samples in slump experiment, (a) group A which are made by ordinary water and (b) group $\mathrm{B}$ which are made by magnetic water

Table 1: Subsidence rate of samples in slump experiment

\begin{tabular}{lc}
\hline Samples & Slump (cm) \\
\hline Nonmagnetic group (A) & 4 \\
Magnetic group (B) & 11 \\
\hline
\end{tabular}

carried out (Fig. 4). Due to lack of enough moulds, concrete was made in the same mixture design in several phases and slump experiment was repeated.

Table 1 shows the experimental results carried out for subsidence rate of group (A) and (B) samples in slump experiment. After making both kinds of concrete with high efficiency and smoothness which is achieved in slump experiment, samples were placed in cube and cylinder moulds in 3 layers by special mallets.

After $24 \mathrm{~h}$ the samples were brought out of the moulds and were exposed by 25 temperature water. The water of this pond was ordinary water for both groups. In the new series of experiments different conditions of water of the pond are going to be applied. After 7 days some of the samples from both groups were placed under pressure. After 28 days compressive strength experiment was carried out on the rest of the samples. The results from the average rates of these experiments are shown in Table 2. 
Table 2: Compressive strength of cylindrical and cubic samples within 7 and 28 days for nonmagnetic and magnetic group

\begin{tabular}{|c|c|c|c|c|}
\hline \multirow[b]{3}{*}{ Samples } & \multicolumn{4}{|c|}{ Compressive strength $\left(\mathrm{kg} \mathrm{m}^{-3}\right)$} \\
\hline & \multicolumn{2}{|c|}{ Cylindrical samples } & \multicolumn{2}{|c|}{ Cubic samples } \\
\hline & 7 days & 28 days & 7 days & 28 days \\
\hline Group A (Nonmagnetic) & 180 & 265 & 125 & 185 \\
\hline Group B (Magnetic) & 220 & 325 & 160 & 225 \\
\hline
\end{tabular}

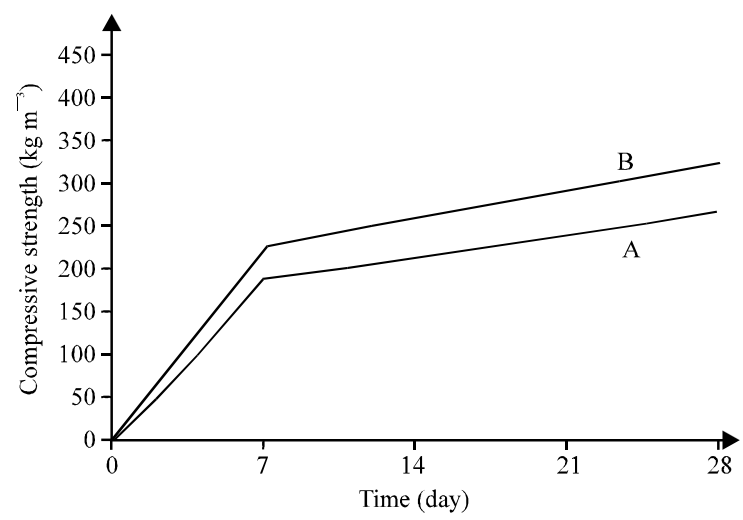

Fig. 5: Compressive strength changes for cylindrical samples for group (A) and (B)

The graph resulted from these changes is shown in Fig. 5. It can be shown from Fig. 5 and Table 2 that the magnetic water does increase plastic properties of concrete. Hence, it is the advantages of this method in comparison to other mehods which increase plasticity of concrete. Also the results of slump experiments show that magnetic field has a considerable effect on clusters of water molecules which means water molecules scattered more from each other. This causes participation of water molecules in cement hydration reaction. So, cement particles are scattered inside concrete mix in form of complex of molecules and hydration reaction initially take place in surface of cement particles. Therefore, a soft layer of hydration reaction products forms on cement particles that prevents from penetration of water molecules to material bulk (Fig. 4b). Concrete made by magnetic water, in comparison with concrete made from plastic substances has several advantages such as its low expense, limitation of added substances, high durability of the machine without decrease in its magnetic energy. Also there is no need for repair, service or any other operations. Based on the experimental results the magnetic concrete have the following advantages as well:
- It increases the efficiency of concrete

- Decrease in the volume of water becomes quite possible

- It prevents the particles from accumulation in 1 place and this in its turn leads to a better distribution of them

- As the most important advantage, it increases the compressive strength of concrete by $25 \%$ and its traction strength by $40 \%$

- Concrete made in this way is more resistant against freezing and more impermeable

- Decrease in water surface tension in magnetic water by $10 \%$ in comparison with ordinary water

\section{CONCLUSION}

Researchers have investigated the effect of magnetic water on strength parameters of concrete. Based on the research magnetic water caused the average compressive strength of samples have $23 \%$ more than that of samples made by ordinary water. The experimental results have also show the advantages of magnetic samples in concrete industry because of increase in plasticity, the efficiency and resistant in comparison with nonmagnetic samples.

\section{REFERENCES}

Al-Qahtani, H., 1996. Effect of magnetic treatment on Gulf seawater. Desalination, 107: 75-81.

Coey, J.M.D. and S. Cass, 2000. Magnetic water treatment. J. Magnetism Magn. Mater., 209: 71-74.

Gholizadeh, M., H. Arabshahi, M.R. Saeidi and B. Mahdavi, 2008. The effect of magnetic water on growth and quality improvement of poultry. Middle-East J. Sci. Res., 3: 140-144.

Kristina, M., 2001. Industrial process Water Treatment. Filtar. Sepration, 38: 32-35.

Munger, J.W., C. Tiller and M.R. Hoffmann, 1986. Identification of Hydroxymethanesulfonate in Fog Water. Water Res., 231: 247-249.

Russell, L.H., J.W. King and G.R. List, 1997. Industerial and Engineering Chemistry. Ind. Eng. Chem. Res., 36: 932-935.

Strum, W. and J.P. Morgan, 1940. Aquatic Chemistry. Wiley-Interscience, New York. 